\title{
Mortality and treatment costs of hospitalized chronic kidney disease patients between the three major health insurance schemes in Thailand
}

Sirirat Anutrakulchai ${ }^{1 *}$, Pisaln Mairiang ${ }^{1}$, Cholatip Pongskul ${ }^{1}$, Kaewjai Thepsuthammarat ${ }^{2}$, Chitranon Chan-on ${ }^{1}$ and Bandit Thinkhamrop ${ }^{3^{*}}$

\begin{abstract}
Background: Thailand has reformed its healthcare to ensure fairness and universality. Previous reports comparing the fairness among the 3 main healthcare schemes, including the Universal Coverage Scheme (UCS), the Civil Servant Medical Benefit Scheme (CSMBS) and the Social Health Insurance (SHI) have been published. They focused mainly on provision of medication for cancers and human immunodeficiency virus infection. Since chronic kidney disease (CKD) patients have a high rate of hospitalization and high risk of death, they also require special care and need more than access to medicine. We, therefore, performed a 1-year, nationwide, evaluation on the clinical outcomes (i.e., mortality rates and complication rates) and treatment costs for hospitalized CKD patients across the 3 main health insurance schemes.

Methods: All adult in-patient CKD medical expense forms in fiscal 2010 were analyzed. The outcomes focused on were clinical outcomes, access to special care and equipment (especially dialysis), and expenses on CKD patients. Factors influencing mortality rates were evaluated by multiple logistic regression.

Results: There were 128,338 CKD patients, accounting for 236,439 admissions. The CSMBS group was older on average, had the most severe co-morbidities, and had the highest hospital charges, while the UCS group had the highest rate of complications. The mortality rates differed among the 3 insurance schemes; the crude odds ratio (OR) for mortality was highest in the CSMBS scheme. After adjustment for biological, economic, and geographic variables, the UCS group had the highest risk of in-hospital death (OR 1.13;95\% confidence interval (Cl) 1.07-1.20; $p<0.001$ ) while the SHI group had lowest mortality (OR 0.87; 95\% Cl 0.76-0.99; $p=0.038$ ). The circumscribed healthcare benefits and limited access to specialists and dialysis care in the UCS may account for less favorable comparison with the CSMBS and SHI groups.
\end{abstract}

Conclusions: Significant differences are observed in mortality rates among CKD patients from among the 3 main healthcare schemes. Improvements in equity of care might minimize the differences.

Keywords: Healthcare equity, Healthcare scheme, Chronic kidney disease, Endstage renal disease, Dialysis

\footnotetext{
*Correspondence: sirirt_a@kku.ac.th; bandit@kku.ac.th

The original version of this article was revised to provide an updated Table 1.

'Department of Medicine, Faculty of Medicine, Khon Kaen University, Khon

Kaen Province 40002, Thailand

${ }^{3}$ Department of Biostatistics and Demography, Faculty of Public Health, Khon

Kaen University, Khon Kaen Province 40002, Thailand

Full list of author information is available at the end of the article
} 


\section{Background}

Thailand implemented healthcare reforms in 2002 to ensure universal healthcare provision [1]. The 4 national healthcare insurance schemes include: (i) the Universal Coverage Scheme (UCS) provides free medical care for persons without any other insurance (i.e., > 70\% of the population: the majority of farmers, low-income persons, and the unemployed); (ii) the Civil Servant Medical Benefit Scheme (CSMBS) provides free medical care for government employees and their dependents; (iii) the Social Health Insurance (SHI) scheme for private sector employees; and, (iv) private insurance. The first 3 schemes cover $>96 \%$ of the population [2]

The level of healthcare in Thailand depends on the particular hospital type and location. Community hospitals principally provide primary care and have limited resources for treating complex illnesses. Patients from the latter are sent to general (secondary) and tertiary hospitals, as appropriate. The distribution of hospitals in turn depends on economics and geography. The central region-where the capital is located-has the highest gross domestic product (GDP) per capita ( 158\% of national GDP). By comparison, the respective proportion of national GDP of the Northeast and North is 34 and $45 \%$ [3].

Previous reports-comparing the fairness of healthcare provision among the 3 main healthcare schemes-were mainly on the provision of medication for cancers and HIV/AIDS [4-8]. To our knowledge, there has been no report comparing the different healthcare schemes vis-àvis chronic diseases (i.e., chronic kidney diseases CKD) that require medicine, special care teams, special medical equipment, and hospitalization.

Since CKD patients have an increased rate of hospitalization and a high risk for death $[9,10]$, we evaluated the nationwide healthcare data of hospitalized CKD patients in fiscal year 2010 for practice outcomes of healthcare among the 3 main health insurance schemes. Our particular focus was on differences in (i) clinical outcomes, (ii) access to special care and equipment (notably dialysis), and (iii) budgeting.

\section{Methods}

The data analyzed were from (i) the in-patients total medical expense forms from the UCS fiscal year 2010 from the National Health Security Office; (ii) the inpatient data from the CSMBS from the Comptroller General's Department; and, (iii) the in-patient data from the SHI from the Social Security Office. The variables included: sex, age, occupation, address, type of hospital, health insurance scheme, co-morbidities, length of hospital stay (days), complications, treatment, clinical outcomes, and medical expenses (costs charged). Additional information obtained from the Nephrology Society of
Thailand, the National Statistical Office, and the Office of the National Economic and Social Development Board, Office of the Prime Minister included: ratio of nephrologists to dialysis units/regional population and end-stage renal disease (ESRD) patients, and the reimbursement of renal replacement therapies among the different healthcare schemes.

The in-patient data were first checked for accuracy by examining for (i) overlapping information (ii) visit dates (iii) missing items (iv) incorrect coding and (v) the correct fiscal year. CKD patients were identified in either the primary diagnosis (CKD-primary) or secondary diagnosis (CKD-secondary) as code N18 of the International Statistical Classification of Diseases and Related Health Problems, 10th revision (ICD-10) [11]. Hemodialysis and peritoneal dialysis were identified as code 39.95 and 54.98 , respectively (ICD-9-CM 2010 classification of procedures) [12]. The data were analyzed not only on the basis of health insurance scheme but also on the level of care provided (i.e., community/primary, general/secondary or tertiary hospital or private hospital) in order to assess accessibility to appropriate care.

\section{Outcome measures}

The differences across the 3 health insurance schemes vis-à-vis in-hospital mortality and high treatment cost were examined. Demographic data, comorbidities and complications were analyzed as to whether they affected the two measures. In addition, policies involving the CKD treatment of the three schemes, budget allocation were explored to facilitate the explanation of the differences of the outcome measures (if any).

\section{Statistical analysis}

STATA version 14 was used for the statistical analyses. The means \pm SD or medians (25th-75th percentile) and percentages were used to present the continuous and categorical data, respectively. The generalized estimating equation (GEE) and multiple logistic regression analysis (MLRA) were performed to adjust the odds ratios for factors influencing the (i) high cost accounting for multiple admissions within an individual and (ii) mortality rate at individual level.

\section{Results \\ Demographic data of the patients}

In fiscal 2010, the population over 19 years of age numbered $47,966,734$ - or $74 \%$ of Thailand's total population of 64.7 million. Approximately $96 \%$ of the adult population $(46,208,964$ persons) was covered by one of the 3 health insurance systems. The total number of adult inpatients was 3,876,792 (admitted 4,863,935 times), accounting for $71 \%$ of all in-patients. According to the 23 major disease groups in the ICD 10, among the 
Table 1 Characteristics of CKD patients by the main three health schemes

\begin{tabular}{|c|c|c|c|}
\hline \multirow[t]{2}{*}{ Characteristics } & \multicolumn{3}{|c|}{ The main three Thai health schemes } \\
\hline & $\begin{array}{l}\text { Universal } \\
\text { Coverage } \\
\text { Scheme }\end{array}$ & $\begin{array}{l}\text { Civil Servant } \\
\text { Medical Benefit } \\
\text { Scheme }\end{array}$ & $\begin{array}{l}\text { Social Health } \\
\text { Insurance }\end{array}$ \\
\hline $\begin{array}{l}\text { Number of adult } \\
\text { patients (persons) }\end{array}$ & 98,727 & 24,767 & 4844 \\
\hline $\begin{array}{l}\text { Number of } \\
\text { admissions (times) }\end{array}$ & 185,161 & 42,348 & 8930 \\
\hline Age $($ mean $\pm S D)$ & $66.55 \pm 13.36$ & $72.23 \pm 11.46$ & $46.99 \pm 12.16$ \\
\hline Sex (male/female) & $1 / 1.15$ & $1 / 0.88$ & $1 / 0.58$ \\
\hline \multicolumn{4}{|l|}{ Region (\%) } \\
\hline $\mathrm{N} / \mathrm{NE} / \mathrm{C} / \mathrm{S}$ & $\begin{array}{l}21.4 / 46.2 / \\
24.2 / 8.2\end{array}$ & $\begin{array}{l}17.4 / 32.6 / \\
39.5 / 10.5\end{array}$ & $\begin{array}{l}11.6 / 11.2 / \\
71.2 / 6.1\end{array}$ \\
\hline \multicolumn{4}{|l|}{ Hospital levels (\%) } \\
\hline $\begin{array}{l}\text { Community } \\
\text { hospital }\end{array}$ & 49.95 & 27.24 & 1.84 \\
\hline General hospital & 23.58 & 24.49 & 16.72 \\
\hline Tertiary hospital & 22.92 & 48.14 & 35.61 \\
\hline Private hospital & 3.55 & 0.13 & 45.83 \\
\hline $\begin{array}{l}\text { Onetime admission/ } \\
\text { Multiple admission (\%) }\end{array}$ & $62.6 / 37.4$ & $64.8 / 35.2$ & $60.0 / 40.0$ \\
\hline $\begin{array}{l}\text { CKD diagnosed as } \\
\text { primary/secondary (\%) }\end{array}$ & $24.4 / 75.6$ & 19.9/80.1 & $35.1 / 64.9$ \\
\hline $\begin{array}{l}\text { Proportion of } \\
\text { ESRD ((\%) }\end{array}$ & 24.19 & 31.63 & 52.06 \\
\hline \multicolumn{4}{|l|}{$\begin{array}{l}\text { Common } \\
\text { co-morbidities (\%) }\end{array}$} \\
\hline Hypertension & 56.91 & 67.90 & 63.79 \\
\hline Diabetes mellitus & 45.08 & 49.09 & 36.50 \\
\hline Hyperlipidemia & 17.19 & 25.05 & 20.05 \\
\hline $\begin{array}{l}\text { Ischemic heart } \\
\text { disease }\end{array}$ & 13.49 & 21.68 & 11.91 \\
\hline Heart failure & 14.28 & 13.95 & 12.70 \\
\hline Gout & 10.49 & 13.17 & 6.44 \\
\hline Sepsis & 12.78 & 14.71 & 10.90 \\
\hline Pneumonia & 9.94 & 12.25 & 8.20 \\
\hline Acute kidney injury & 8.59 & 10.26 & 7.23 \\
\hline Diarrhea & 8.63 & 8.34 & 7.51 \\
\hline Stroke & 6.51 & 11.41 & 5.66 \\
\hline Respiratory failure & 8.53 & 7.85 & 4.81 \\
\hline \multicolumn{4}{|l|}{ Complications (\%) } \\
\hline $\begin{array}{l}\text { Anemia requiring } \\
\text { blood transfusion }\end{array}$ & 31.86 & 23.24 & 31.32 \\
\hline Hyperkalemia & 15.95 & 11.56 & 11.50 \\
\hline Volume overload & 12.44 & 8.96 & 14.80 \\
\hline Metabolic acidosis & 9.20 & 5.04 & 4.81 \\
\hline
\end{tabular}

Table 1 Characteristics of CKD patients by the main three health schemes (Continued)

Dialysis treatment

(\% of admissions)

$\begin{array}{clll}\text { Hemodialysis } & 6.97 & 16.64 & 24.15 \\ \text { Peritoneal dialysis } & 2.98 & 1.86 & 2.15 \\ \text { Overall mortality } & 10.39 & 12.44 & 8.71\end{array}$

rate (\%)

Mortality rate in

different hospital

levels (\%)

$\begin{array}{llll}\text { Community/ } & 3.7 / 14.9 / 17.5 / & 5.9 / 14.5 / 15.1 / & 7.9 / 8.04 / \\ \text { General/Tertiary/ } & 13.2 & 15.2 & 10.4 / 7.6 \\ \text { Private } & & & \end{array}$

Note: $C K D$ chronic kidney disease, ESRD end stage renal disease, $N$ northern region, $N E$ northeastern region, $C$ central region, $S$ southern region, $S D$ standard deviation

respective causes of hospitalization and mortality, diseases of the genitourinary system ranked 7th among hospitalized patients $(298,258$ persons, $7.7 \%$ of all adults in-patients and 392,498 admissions) and the 7th cause of mortality [13].

CKD was the most common diagnosis of the genitourinary system. The total number of CKD patients was 128,338 (generating 236,439 admissions), and accounting for $4.9 \%$ of all adult in-patient admissions (268 persons or 493 visits per 100,000 adult population). Of these, 98,727 persons (185,161 admissions), 24,767 (42,348 admissions) and 4844 (8930 admissions) were covered in the UCS, CSMBS, and SHI groups, respectively.

\section{Characteristics of hospitalized CKD patients under different healthcare schemes}

Table 1 presents the characteristics of CKD patients in the UCS, CSMBS, and SHI schemes. The age of subjects in the CSMBS were the oldest while those in the SHI scheme were the youngest. Most of participants in the UCS, CSMBS and SHI scheme were admitted in a community, tertiary and private hospital, respectively. The patients in the CSMBS and SHI scheme comprised the majority from the central region while those in the UCS were from the Northeast region. Highest proportion of CKD patients in the CSMBS group was diagnosed as CKD-secondary. The respective proportion of ESRD among in-patients under the SHI, CSMBS and UCS was 52.1, 31.6, and $24.2 \%$.

\section{Associated co-morbidities}

The top 12 diseases associated with CKD patients were hypertension (HT) (59.3\%), diabetes mellitus (DM) (45.5\%), hyperlipidemia (18.8\%), ischemic heart disease (15.0\%), heart failure (14.2\%), sepsis (13.1\%), gout (10.9\%), pneumonia (10.3\%), acute kidney injury on top CKD (8.9\%), diarrhea (8.5\%), respiratory failure $(8.3 \%)$ 
and stroke (7.4\%). Patients in the CSMBS had the greatest proportion of co-morbidities (Table 1).

\section{Complications}

Complications for all CKD patients comprised significant anemia requiring blood transfusion (30.2\%), hyperkalemia (14.9\%), volume overload (11.9\%), and metabolic acidosis (8.2\%). The rate of complications was highest in the UCS (Table 1).

\section{Dialysis treatment}

CKD patients needed dialysis, accounting for 15,684 (12.2\%) patients. The mode of dialysis included hemodialysis $(n=12,175 ; 77.6 \%)$ and peritoneal dialysis $(n=3509 ; 23.4 \%)$. The percentage of those needing hemodialysis was greater under the SHI and CSMBS than the UCS (Table 1). The respective proportion of ESRD patients receiving both types of dialysis during admission under the UCS, SHI and CSMBS was 41.1, 50.5, and $58.5 \%$.

The characteristics of CKD patients defined as CKDprimary or CKD-secondary and admitted in different hospital levels are presented in the Additional file 1: Table S1 and Additional file 2: Table S2. Subjects in the CKD-secondary group were older, stayed in hospital longer, were more likely from the central region and were admitted to a tertiary hospital. The CKD-secondary group also had more co-morbidities, incurred a higher hospital cost, and had higher mortality rate than the CKD-primary group. In contrast, the rate of complications was higher in the CKD-primary group. Patients treated in tertiary hospitals had more comorbidities; particularly cardiovascular disease, pneumonia, acute on

Table 2 Length of hospital stay and hospital charges for CKD patients by region, hospital level and healthcare scheme

\begin{tabular}{|c|c|c|c|c|}
\hline & \multicolumn{2}{|c|}{ Length of hospital stays (Days) } & \multicolumn{2}{|c|}{ Hospital charges (Baht) } \\
\hline & Mean \pm SD & Median (25th-75th percentile) & Mean \pm SD & Median (25th-75th percentile) \\
\hline \multicolumn{5}{|l|}{ Insurance } \\
\hline UCS & $5.14 \pm 8.01$ & $3.00(2.00-6.00)$ & $16,040 \pm 131,052$ & $6506(3599-13,562)$ \\
\hline CSMBS & $9.40 \pm 17.81$ & $5.00(3.00-10.00)$ & $39,401 \pm 113,206$ & $12,685(5694-31,169)$ \\
\hline SHI & $7.49 \pm 11.11$ & $4.00(3.00-8.00)$ & $36,053 \pm 87,854$ & $14,745(6773-33,588)$ \\
\hline \multicolumn{5}{|l|}{ Region } \\
\hline Northern & $5.46 \pm 7.41$ & $3.00(2.00-6.00)$ & $15,626 \pm 38,605$ & $6796(3660-14,335)$ \\
\hline Northeast & $4.56 \pm 7.21$ & $3.00(2.00-5.00)$ & $13,292 \pm 164,746$ & $5827(3378-11,507)$ \\
\hline Central & $8.50 \pm 15.74$ & $5.00(2.00-9.00)$ & $37,717 \pm 114,169$ & $12,549(5747-30,348)$ \\
\hline Southern & $6.61 \pm 10.91$ & $4.00(2.00-7.00)$ & $19,443 \pm 47,700$ & $7847(4111-17,058)$ \\
\hline \multicolumn{5}{|l|}{ Hospital levels } \\
\hline Community (All schemes) & $4.02 \pm 4.93$ & $3.00(2.00-5.00)$ & $7683 \pm 144,783$ & $4482(2830-7548)$ \\
\hline - UCS & $3.78 \pm 4.43$ & $3.00(1.00-5.00)$ & $7196 \pm 154,018$ & 4349 (2775-7196) \\
\hline - CSMBS & $5.85 \pm 7.36$ & $4.00(3.00-7.00)$ & $11,150 \pm 24,473$ & $5816(3387-10,636)$ \\
\hline$-\mathrm{SHI}$ & $6.89 \pm 10.35$ & $4.00(3.00-8.00)$ & $19,013 \pm 35,546$ & $8594(4922-20,042$ \\
\hline General (All schemes) & $6.56 \pm 9.52$ & $4.00(2.00-7.00)$ & $19,556 \pm 119,149$ & $9251(4967-18,832)$ \\
\hline - UCS & $5.97 \pm 8.77$ & $4.00(2.00-7.00)$ & $17,969 \pm 130,809$ & 8807 (4808-17,531) \\
\hline - CSMBS & $9.08 \pm 12.05$ & $6.00(3.00-10.00)$ & $26,606 \pm 56,668$ & $12,179(6162-25,407)$ \\
\hline$-\mathrm{SHI}$ & $6.85 \pm 8.56$ & $4.00(3.00-8.00)$ & $18,754 \pm 45,335$ & $7823(4152-17,042)$ \\
\hline Tertiary (All schemes) & $8.64 \pm 16.35$ & $5.00(2.00-9.00)$ & $38,758 \pm 102,610$ & $14,404(6998-32,997)$ \\
\hline - UCS & $7.21 \pm 11.68$ & $4.00(2.00-8.00)$ & $28,033 \pm 65,349$ & $12,043(6312-25,825)$ \\
\hline - CSMBS & $11.71 \pm 23.47$ & $6.00(3.00-12.00)$ & $62,964 \pm 154,866$ & $22,389(10,214-54,582)$ \\
\hline$-\mathrm{SHI}$ & $8.65 \pm 12.90$ & $5.00(3.00-9.00)$ & $31,367 \pm 71,631$ & $12,724(5761-28,578)$ \\
\hline Private (All schemes) & $5.57 \pm 8.85$ & $3.00(2.00-6.00)$ & $43,915 \pm 104,269$ & $20,608(9725-37,617)$ \\
\hline - UCS & $4.83 \pm 7.71$ & $2.00(1.00-5.00)$ & $42,401 \pm 101,864$ & $20,611(9415-33,539)$ \\
\hline - CSMBS & $8.46 \pm 13.55$ & $5.00(3.00-7.00)$ & $30,826 \pm 71,164$ & $11,732(7139-24,025)$ \\
\hline$-\mathrm{SHI}$ & $6.86 \pm 10.40$ & $4.00(3.00-7.00)$ & $46,805 \pm 108,756$ & $20,820(10,395-44,565)$ \\
\hline
\end{tabular}

Note: CKD chronic kidney disease, UCS Universal Coverage Scheme, CSMBS Civil Servant Medical Benefit Scheme, SHI Social Health Insurance, SD standard deviation 
Table 3 Factors influencing high hospital charges (>50,000 baht/1470 USD) among hospitalized, Thai, adult, CKD patients

\begin{tabular}{|c|c|c|c|c|c|c|}
\hline Variables & $\begin{array}{l}\text { No. of admission } \\
\text { (times) }\end{array}$ & $\begin{array}{l}\text { No. of high cost } \\
\text { admission (\%) }\end{array}$ & $\begin{array}{l}\text { Crude odds ratio } \\
(95 \% \mathrm{Cl})\end{array}$ & $p$-value & $\begin{array}{l}\text { Adjusted odds ratio } \\
(95 \% \mathrm{Cl})\end{array}$ & $p$-value \\
\hline \multicolumn{7}{|l|}{ Sex } \\
\hline Female & 126,027 & $8490(6.7)$ & 1 & $<0.001$ & 1 & $<0.001$ \\
\hline Male & 110,412 & $9662(8.8)$ & $1.31(1.27-1.36)$ & & $1.16(1.12-1.20)$ & \\
\hline \multicolumn{7}{|l|}{ Age } \\
\hline 19-30 & 4376 & 405 (9.3) & 1 & & 1 & \\
\hline $31-40$ & 8392 & $715(8.5)$ & $0.92(0.80-1.06)$ & 0.24 & $1.03(0.88-1.20)$ & 0.70 \\
\hline $41-50$ & 22,172 & $1682(7.6)$ & $0.81(0.72-0.92)$ & 0.001 & $1.08(0.94-1.24)$ & 0.26 \\
\hline $51-60$ & 46,571 & 3408 (7.3) & $0.77(0.68-0.86)$ & $<0.001$ & $1.05(0.92-1.20)$ & 0.49 \\
\hline $61-70$ & 62,672 & $4324(6.9)$ & $0.72(0.64-0.81)$ & $<0.001$ & $1.01(0.89-1.16)$ & 0.85 \\
\hline $71-80$ & 64,288 & 5065 (7.9) & $0.82(0.72-0.92)$ & 0.001 & $1.02(0.89-1.16)$ & 0.82 \\
\hline$>80$ & 27,968 & $2553(9.1)$ & $0.95(0.84-1.07)$ & 0.40 & $1.01(0.88-1.17)$ & 0.85 \\
\hline \multicolumn{7}{|l|}{ Insurance } \\
\hline CSMBS & 42,348 & $6923(16.4)$ & 1 & & 1 & \\
\hline $\mathrm{SHI}$ & 8930 & $1441(16.1)$ & $0.99(0.93-1.06)$ & 0.85 & $0.45(0.41-0.49)$ & $<0.001$ \\
\hline UCS & 185,161 & 9788 (5.3) & $0.29(0.28-0.30)$ & $<0.001$ & $0.38(0.36-0.39)$ & $<0.001$ \\
\hline \multicolumn{7}{|l|}{ Hospital level } \\
\hline Community & 102,251 & $977(1.0)$ & 1 & & 1 & \\
\hline General & 56,525 & $4049(7.2)$ & $7.54(7.03-8.10)$ & $<0.001$ & $3.58(3.32-3.87)$ & $<0.001$ \\
\hline Tertiary & 66,150 & $10,974(16.6)$ & $19.36(18.11-20.70)$ & $<0.001$ & $7.17(6.67-7.70)$ & $<0.001$ \\
\hline Private & 11,513 & $2152(18.7)$ & $23.09(21.28-25.05)$ & $<0.001$ & $13.82(12.58-15.19)$ & $<0.001$ \\
\hline \multicolumn{7}{|l|}{ Region } \\
\hline Northern & 48,110 & $2645(5.5)$ & 1 & & 1 & \\
\hline Northeast & 104,067 & $3703(3.6)$ & $0.63(0.60-0.66)$ & $<0.001$ & $0.74(0.70-0.78)$ & $<0.001$ \\
\hline Central & 64,962 & $10,360(16.0)$ & $3.23(3.08-3.39)$ & $<0.001$ & $1.83(1.74-1.94)$ & $<0.001$ \\
\hline Southern & 19,300 & $1444(7.5)$ & $1.36(1.27-1.46)$ & $<0.001$ & $1.21(1.12-1.31)$ & $<0.001$ \\
\hline \multicolumn{7}{|l|}{ Co-morbidities } \\
\hline Hypertension (yes/no) & $125,565 / 110,874$ & 11,037 (8.8)/7115 (6.4) & $1.38(1.34-1.42)$ & $<0.001$ & $1.00(0.96-1.04)$ & 0.96 \\
\hline Diabetes mellitus (yes/no) & $101,664 / 134,775$ & 8775 (8.6)/9377 (7.0) & $1.27(1.23-1.31)$ & $<0.001$ & $1.12(1.08-1.17)$ & $<0.001$ \\
\hline Hyperlipidemia (yes/no) & $31,229 / 205,210$ & $3449(11.0) / 14,703(7.2)$ & $1.51(1.45-1.57)$ & $<0.001$ & $1.06(1.01-1.12)$ & 0.016 \\
\hline $\begin{array}{l}\text { Ischemic heart disease } \\
\text { (yes/no) }\end{array}$ & $29,272 / 207,167$ & $4406(15.1) / 13,746(6.6)$ & $2.42(2.33-2.51)$ & $<0.001$ & $1.75(1.67-1.84)$ & $<0.001$ \\
\hline Heart failure (yes/no) & $24,915 / 211,524$ & $2679(10.8) / 15,473(7.3)$ & $1.53(1.46-1.60)$ & $<0.001$ & $1.11(1.05-1.17)$ & $<0.001$ \\
\hline Gout (yes/no) & $19,640 / 216,799$ & $1407(7.2) / 16,745(7.7)$ & $0.92(0.87-0.98)$ & 0.005 & $0.99(0.93-1.06)$ & 0.76 \\
\hline Sepsis (yes/no) & $18,528 / 217,911$ & $4586(24.8) / 13,566(6.2)$ & $4.62(4.44-4.79)$ & $<0.001$ & $2.75(2.62-2.88)$ & $<0.001$ \\
\hline Pneumonia (yes/no) & $14,732 / 221,707$ & $4004(27.2) / 14,148(6.4)$ & $5.18(4.98-5.40)$ & $<0.001$ & $3.27(3.10-3.45)$ & $<0.001$ \\
\hline $\begin{array}{l}\text { Acute renal failure } \\
\text { (yes/no) }\end{array}$ & $12,133 / 224,306$ & $3351(27.6) / 14,801(6.6)$ & $5.09(4.88-5.31)$ & $<0.001$ & $2.35(2.23-2.48)$ & $<0.001$ \\
\hline Diarrhea (yes/no) & $12,085 / 224,354$ & $774(6.4) / 17,378$ (7.75) & $0.82(0.76-0.88)$ & $<0.001$ & $0.98(0.90-1.07)$ & 0.69 \\
\hline Stroke (yes/no) & $11,886 / 224,553$ & $2313(19.5) / 15,839(7.1)$ & $2.97(2.83-3.12)$ & $<0.001$ & $1.82(1.72-1.94)$ & $<0.001$ \\
\hline Respiratory failure (yes/no) & $11,347 / 225,092$ & $3080(27.1) / 15,072(6.7)$ & $5.02(4.80-5.25)$ & $<0.001$ & $2.30(2.17-2.44)$ & $<0.001$ \\
\hline \multicolumn{7}{|l|}{ Complications } \\
\hline $\begin{array}{l}\text { Anemia requiring blood } \\
\text { Transfusion (yes/no) }\end{array}$ & $57,727 / 178,712$ & $7442(12.9) / 10,710$ (6.0) & $2.38(2.31-2.46)$ & $<0.001$ & $2.25(2.17-2.34)$ & $<0.001$ \\
\hline Hyperkalemia (yes/no) & $23,505 / 212,934$ & $2532(10.8) / 15,620(7.3)$ & $1.57(1.51-1.64)$ & $<0.001$ & $1.17(1.11-1.23)$ & $<0.001$ \\
\hline
\end{tabular}


Table 3 Factors influencing high hospital charges (>50,000 baht/1470 USD) among hospitalized, Thai, adult, CKD patients (Continued)

\begin{tabular}{|c|c|c|c|c|c|c|}
\hline Volume overload (yes/no) & $22,091 / 214,348$ & $1966(8.9) / 16,186(7.55)$ & $1.30(1.24-1.36)$ & $<0.001$ & $0.99(0.93-1.05)$ & 0.67 \\
\hline $\begin{array}{l}\text { Metabolic acidosis } \\
\text { (yes/no) }\end{array}$ & $11,897 / 224,542$ & $1549(13.0) / 16,603(7.4)$ & $1.90(1.80-2.00)$ & $<0.001$ & $1.11(1.04-1.19)$ & 0.003 \\
\hline \multicolumn{7}{|l|}{ Mode of dialysis } \\
\hline Hemodialysis & $17,143 / 219,296$ & $5239(30.6) / 12,913(5.9)$ & $6.45(6.22-6.70)$ & $<0.001$ & $3.14(3.00-3.28)$ & $<0.001$ \\
\hline Peritoneal dialysis & $4584 / 231,855$ & $1170(25.5) / 16,982(7.3)$ & $4.16(3.89-4.46)$ & $<0.001$ & $3.30(3.04-3.59)$ & $<0.001$ \\
\hline
\end{tabular}

Note: CKD chronic kidney disease, UCS Universal Coverage Scheme, CSMBS Civil Servant Medical Benefit Scheme, SHI Social Health Insurance, CI confidence interval

top CKD, and sepsis. By region, hospitals admitting the greatest proportion of CKD patients were in the North and Northeast in community hospitals. By comparison, patients in the central region were admitted to tertiary hospitals. Most of the private hospitals are also located in the central region, where a significant number of patients in the SHI group were admitted.

\section{Length of hospital stay}

The longest hospital stay among CKD patients was in the central region at tertiary hospitals under the CSMBS (Table 2).

\section{Factors influencing the high treatment cost of in-patient} Hospital charges for CKD patients were highest in (i) the central region compared with other regions (ii) at private hospitals compared with community, general and tertiary hospitals, and (iii) covered by CSMBS compared with UCS and SHI (Table 2). Comparing hospital charges of the 3 health schemes with the same hospital levels revealed that hospital charge of the SHI was significantly highest at community hospitals while the CSMBS was the highest at general and tertiary hospitals. No significant differences in hospital charges between the 3 health schemes treated at private hospitals were observed (Table 2).

After adjustment with the factors affecting high hospital charges ( $>50,000$ baht or $\sim 1470$ USD per admission)_sex, hospital level, region, co-morbidities, complications, and dialysis treatment-the UCS and SHI groups had a respective 62 and 55\% lower hospital charges than the CSMBS (Table 3).

\section{Factors associated with mortality}

Table 4 presents patient characteristics. After adjustment for age, sex, region, hospital level, hospital charge, comorbidities, complications, and mode of dialysis, the multiple logistic regression analysis revealed that the highest mortality rate was for patients under the UCS while the lowest was for those under the SHI. Patients under the SHI and CSMBS had a respective 23.0 and $11.5 \%$ reduction of mortality rates compared to the UCS group.
Patients who received dialysis had a reduced mortality (hemodialysis; OR 0.90, 95\% CI 0.85-0.96, $p=0.002$, peritoneal dialysis; OR $0.87,95 \%$ CI $0.78-0.96, p=0.006$ ). Other factors influencing the mortality rate included (i) elderly age (ii) level of care (i.e., tertiary hospitals had higher mortality rates than general and private hospitals while community hospital had lowest rate); (iii) presence of ESRD; (iv) co-morbidities (viz., sepsis, respiratory failure, stroke, pneumonia, acute on top CKD, ischemic heart disease, heart failure, and DM); and (v) complications of CKD (i.e., metabolic acidosis, hyperkalemia and volume overload) (Table 5).

In addition to the factors associated with mortality, health policies among the health schemes differed (Table 6). Patients in the UCS trended to have fewer benefits than patients in the other healthcare schemes. Patients under the UCS were not able to choose the hospitals with full-scale CKD care. They had to be referred by a primary care hospital. The limited distribution of nephrologists and dialysis units outside major urban centres might be a barrier for patients under the UCS who live mainly in the North and Northeast (Table 7).

\section{Discussion}

CKD is defined as abnormalities in the kidney structure or function and/or a decreased glomerular filtration rate for more than 3 months $\left(\right.$ GFR $<60 \mathrm{ml} / \mathrm{min} / 1.73 \mathrm{~m}^{2}$ ) [14]. Code N18 in the ICD-10 represents an older nomenclature for chronic renal failure as a decrease in GFR comparable to stage 3a-5 CKD patients (estimated GFR $<60 \mathrm{ml} / \mathrm{min} / 1.73 \mathrm{~m}^{2}$ ). Our study revealed that $45-$ $60 \%$ of admitted CKD patients also had hypertension and diabetes. The co-morbidities associated with mortality and high hospital charges were sepsis, pneumonia, respiratory failure followed by cardiovascular diseases and AKI on pre-existing CKD. This finding agrees with previous studies that demonstrated the severity of CKD increased in-hospital mortality among patients with acute coronary syndrome [15-20], heart failure [21-23], cardiac surgery [24], and stroke [25]. Early optimum therapeutic interventions and appropriate medications 
Table 4 Characteristics of dead and alive hospitalized CKD patients

\begin{tabular}{|c|c|c|c|}
\hline \multirow[t]{2}{*}{ Characteristics } & \multicolumn{3}{|c|}{ Discharge status of CKD patients } \\
\hline & $\begin{array}{l}\text { Dead CKD } \\
\text { patients }\end{array}$ & $\begin{array}{l}\text { Alive CKD } \\
\text { patients }\end{array}$ & $p$-value \\
\hline $\begin{array}{l}\text { Number of patients } \\
\text { (persons) }\end{array}$ & 13,755 & 114,583 & \\
\hline Age (years; mean $\pm S D$ ) & $67.89 \pm 14.04$ & $66.79 \pm 13.70$ & $<0.001$ \\
\hline Sex (male/female) & $1 / 0.98$ & $1 / 1.07$ & $<0.001$ \\
\hline \multicolumn{4}{|l|}{ Health scheme (\%) } \\
\hline UCS/CSMBS/SHI & $74.5 / 22.4 / 3.1$ & $77.2 / 18.9 / 3.9$ & $<0.001$ \\
\hline \multicolumn{4}{|l|}{ Hospital levels (\%) } \\
\hline \multicolumn{4}{|l|}{$\begin{array}{l}\text { Community/General/ } \\
\text { Tertiary/Private }\end{array}$} \\
\hline First admission & $\begin{array}{l}24.6 / 29.7 / 41.0 / \\
4.7\end{array}$ & $\begin{array}{l}46.1 / 22.7 / 26.7 / \\
4.5\end{array}$ & $<0.001$ \\
\hline Frequent admission & $\begin{array}{l}17.3 / 33.0 / 44.9 / \\
4.8\end{array}$ & $\begin{array}{l}42.7 / 24.2 / 28.5 / \\
4.5\end{array}$ & $<0.001$ \\
\hline Last admission & $\begin{array}{l}14.9 / 34.6 / 45.9 / \\
4.6\end{array}$ & $\begin{array}{l}43.4 / 24.2 / 28.0 / \\
4.4\end{array}$ & $<0.001$ \\
\hline $\begin{array}{l}\text { Onetime admission/Multiple } \\
\text { admission (\%) }\end{array}$ & $54.6 / 45.4$ & $63.9 / 36.1$ & $<0.001$ \\
\hline $\begin{array}{l}\text { CKD diagnosed as primary/ } \\
\text { secondary (\%) }\end{array}$ & $21.7 / 78.3$ & $24.2 / 75.8$ & $<0.001$ \\
\hline Proportion of ESRD ((\%) & 39.29 & 25.16 & $<0.001$ \\
\hline \multicolumn{4}{|l|}{ Common co-morbidities (\%) } \\
\hline Hypertension & 59.54 & 59.26 & 0.52 \\
\hline Diabetes mellitus & 49.40 & 45.06 & $<0.001$ \\
\hline Hyperlipidemia & 17.43 & 18.98 & $<0.001$ \\
\hline Ischemic heart disease & 23.10 & 14.04 & $<0.001$ \\
\hline Heart failure & 23.82 & 13.00 & $<0.001$ \\
\hline Gout & 10.12 & 10.94 & 0.003 \\
\hline Sepsis & 44.68 & 9.29 & $<0.001$ \\
\hline Pneumonia & 28.06 & 8.19 & $<0.001$ \\
\hline Acute kidney injury & 21.61 & 7.33 & $<0.001$ \\
\hline Diarrhea & 8.30 & 8.56 & 0.31 \\
\hline Stroke & 15.06 & 6.51 & $<0.001$ \\
\hline Respiratory failure & 34.22 & 5.14 & $<0.001$ \\
\hline \multicolumn{4}{|l|}{ Complications (\%) } \\
\hline $\begin{array}{l}\text { Anemia requiring blood } \\
\text { transfusion }\end{array}$ & 43.01 & 28.64 & $<0.001$ \\
\hline Hyperkalemia & 27.10 & 13.47 & $<0.001$ \\
\hline Volume overload & 20.58 & 10.81 & $<0.001$ \\
\hline Metabolic acidosis & 20.35 & 6.77 & $<0.001$ \\
\hline \multicolumn{4}{|l|}{ Dialysis treatment (\%) } \\
\hline Hemodialysis & 18.29 & 8.43 & $<0.001$ \\
\hline Peritoneal dialysis & 5.21 & 2.44 & $<0.001$ \\
\hline
\end{tabular}

Table 4 Characteristics of dead and alive hospitalized CKD patients (Continued)

\begin{tabular}{|c|c|c|c|}
\hline $\begin{array}{l}\text { Length of stay } \\
\text { (days; mean } \pm \text { SD) }\end{array}$ & $11.4 \pm 24.8$ & $5.8 \pm 8.8$ & $<0.001$ \\
\hline $\begin{array}{l}\text { Hospital charges } \\
\text { (baht; mean } \pm \text { SD) }\end{array}$ & $61,662 \pm 164,842$ & $18,656 \pm 55,546$ & $<0.001$ \\
\hline
\end{tabular}

might improve clinical outcomes and reduce the cost of hospitalization.

After the Thai healthcare reforms were implemented in 2002 , the poor indeed had wider access to medical services. Equity of health financing, health workers and healthcare infrastructure have been studied and an improving trend in equity was reported [26-29]. Notwithstanding, differences in access to hospital types persist among the 3 insurance schemes. The population under UCS must be registered at a community hospital near home. When necessary, there is a line of referrals. Any patient who does not follow the referral process and attempts to go directly to a tertiary care center will have to pay all costs by themselves. By comparison, under the CSMBS, a government employee can register at any public hospital according to their preference [2] while an employee covered by SHI must register at the contracted public or private hospital [30]. If a referral is required, the employee must go to one of the hospitals in the designated network. Only in an emergency may persons covered by SHI or UCS be exempted from paying; however, they must be transferred to their registered hospital as soon as possible. These vagaries in regulations provide an explanation as to why those on UCS go to community hospitals and government employees go to tertiary care hospitals [2]. Since the UCS group comprises a higher proportion of low socio-economic patients, mainly located in rural region, they experience delayed hospital accessibility. Furthermore, our study revealed differences in clinical outcomes of hospitalized CKD patients that might represent residual inequality that needs addressing.

Mortality rates of hospitalized CKD patients differed among the 3 insurance schemes: the crude odd ratios revealed the highest mortality under the CSMBS. Patients admitted under the CSMBS had more severe or complicated disease than the other schemes; as indicated by the highest (i) percentage of life-threatening co-morbidities, (ii) length of stay, and (iii) hospital charges. After adjusting for biological and economic geographic variables, the multivariable analysis demonstrated that the UCS group had the highest risk of in-hospital death while the SHI group had the lowest mortality. The explanation may be related to the limited health care benefits under the UCS compared to the CSMBS and SHI. Table 6 presents a comparison of the health policies among the 3 schemes. The CSMBS appears 
Table 5 Prognostic factors influencing mortality rates among hospitalized, Thai, adult, CKD patients

\begin{tabular}{|c|c|c|c|c|c|c|}
\hline Variables & $\begin{array}{l}\text { No. of patients } \\
\text { (persons) }\end{array}$ & $\begin{array}{l}\text { Dead persons and mortality } \\
\text { rate (\%) }\end{array}$ & $\begin{array}{l}\text { Crude odds ratio } \\
(95 \% \mathrm{Cl})\end{array}$ & $p$-value & $\begin{array}{l}\text { Adjusted odds ratio } \\
(95 \% \mathrm{Cl})\end{array}$ & $p$-value \\
\hline \multicolumn{7}{|l|}{ Sex } \\
\hline Female & 66,134 & $6814(10.3)$ & 1 & & 1 & \\
\hline Male & 62,204 & 6941 (11.2) & $1.09(1.06-1.13)$ & $<0.001$ & $1.03(0.99-1.07)$ & 0.17 \\
\hline \multicolumn{7}{|l|}{ Age } \\
\hline 19-30 & 1869 & $189(10.1)$ & 1 & & 1 & \\
\hline $31-40$ & 4135 & $400(9.7)$ & $0.95(0.79-1.14)$ & 0.60 & $1.16(0.95-1.42)$ & 0.15 \\
\hline $41-50$ & 10,556 & $1127(10.7)$ & $1.06(0.90-1.25)$ & 0.47 & $1.28(1.07-1.54)$ & 0.008 \\
\hline $51-60$ & 23,073 & $2318(10.0)$ & $0.99(0.85-1.16)$ & 0.93 & $1.21(1.01-1.44)$ & 0.039 \\
\hline $61-70$ & 32,837 & 3277 (10.0) & $0.99(0.84-1.15)$ & 0.85 & $1.25(1.05-1.50)$ & 0.013 \\
\hline $71-80$ & 37,727 & 4039 (10.7) & $1.07(0.91-1.24)$ & 0.42 & $1.40(1.18-1.68)$ & $<0.001$ \\
\hline$>80$ & 18,141 & 2405 (13.3) & $1.36(1.16-1.59)$ & $<0.001$ & $1.82(1.52-2.19)$ & $<0.001$ \\
\hline \multicolumn{7}{|l|}{ Insurance } \\
\hline CSMBS & 24,767 & 3080 (12.4) & 1 & & 1 & \\
\hline UCS & 98,727 & $10,253(10.4)$ & $0.82(0.78-0.85)$ & $<0.001$ & $1.13(1.07-1.20)$ & $<0.001$ \\
\hline $\mathrm{SHI}$ & 4844 & $422(8.7)$ & $0.67(0.60-0.75)$ & $<0.001$ & $0.87(0.76-0.99)$ & 0.038 \\
\hline \multicolumn{7}{|l|}{ Hospital level } \\
\hline Community & 56,151 & $3384(6.0)$ & 1 & & 1 & \\
\hline General & 30,156 & 4091 (13.6) & $2.45(2.33-2.57)$ & $<0.001$ & $1.58(1.50-1.68)$ & $<0.001$ \\
\hline Tertiary & 36,274 & 5634 (15.5) & $2.87(2.74-3.00)$ & $<0.001$ & $1.62(1.53-1.71)$ & $<0.001$ \\
\hline Private & 5757 & $646(11.2)$ & $1.97(1.80-2.15)$ & $<0.001$ & $1.51(1.35-1.68)$ & $<0.001$ \\
\hline \multicolumn{7}{|l|}{ Hospital charges (Baht/USD) } \\
\hline First quartile $(<5550 /<163)$ & 32,090 & $701(2.2)$ & 1 & & 1 & \\
\hline $\begin{array}{l}\text { Second quartile } \\
(5550-13,271 / 163-390)\end{array}$ & 32,079 & $2028(6.3)$ & $3.02(2.77-3.30)$ & $<0.001$ & $2.08(1.90-2.28)$ & $<0.001$ \\
\hline $\begin{array}{l}\text { Third quartile } \\
(13,272-34,502 / 390-1015)\end{array}$ & 32,085 & $3680(11.5)$ & $5.80(5.34-6.30)$ & $<0.001$ & $2.98(2.72-3.26)$ & $<0.001$ \\
\hline $\begin{array}{l}\text { Fourth quartile } \\
(>34,502 />1015)\end{array}$ & 32,084 & $7346(22.9)$ & 13.30 (12.28-14.39) & $<0.001$ & $4.43(4.03-4.88)$ & $<0.001$ \\
\hline $\begin{array}{l}\text { Onetime admission/Multiple } \\
\text { admission }\end{array}$ & $80,764 / 47,574$ & 7514 (9.3)/6241 (13.1) & $1.47(1.42-1.53)$ & $<0.001$ & $0.64(0.61-0.68)$ & $<0.001$ \\
\hline $\begin{array}{l}\text { CKD diagnosed as primary/ } \\
\text { secondary }\end{array}$ & $30,731 / 97,607$ & $2991(9.7) / 10,764(11.0)$ & $1.15(1.10-1.20)$ & $<0.001$ & $0.95(0.90-1.01)$ & 0.11 \\
\hline ESRD (yes/no) & $34,234 / 94,104$ & $5405(15.8) / 8350(8.9)$ & $1.93(1.86-2.00)$ & $<0.001$ & $1.49(1.42-1.57)$ & $<0.001$ \\
\hline \multicolumn{7}{|l|}{ Co-morbidities } \\
\hline Diabetes mellitus (yes/no) & $58,427 / 69,911$ & $6795(11.6) / 6960(10.0)$ & $1.19(1.15-1.23)$ & $<0.001$ & $1.12(1.08-1.17)$ & $<0.001$ \\
\hline $\begin{array}{l}\text { Ischemic heart disease } \\
\text { (yes/no) }\end{array}$ & $19,264 / 109,074$ & 3178 (16.5)/10,577 (9.7) & $1.84(1.76-1.92)$ & $<0.001$ & $1.43(1.35-1.51)$ & $<0.001$ \\
\hline Heart failure (yes/no) & $18,174 / 110,164$ & $3277(18.0) / 10,478$ (9.5) & $2.09(2.01-2.18)$ & $<0.001$ & $1.38(1.31-1.46)$ & $<0.001$ \\
\hline Sepsis (yes/no) & $16,792 / 111,546$ & $6146(36.6) / 7609$ (6.8) & $7.89(7.58-8.20)$ & $<0.001$ & $4.28(4.09-4.48)$ & $<0.001$ \\
\hline Pneumonia (yes/no) & $13,247 / 115,091$ & 3860 (29.1)/9895 (8.6) & $4.37(4.19-4.56)$ & $<0.001$ & $1.59(1.51-1.68)$ & $<0.001$ \\
\hline Acute renal failure (yes/no) & $11,367 / 116,971$ & $2972(26.1) / 10,783(9.2)$ & $3.49(3.33-3.65)$ & $<0.001$ & $1.44(1.36-1.52)$ & $<0.001$ \\
\hline Stroke (yes/no) & $9527 / 118,811$ & $2071(21.7) / 11,684(9.8)$ & $2.55(2.42-2.68)$ & $<0.001$ & $1.85(1.73-1.96)$ & $<0.001$ \\
\hline Respiratory failure (yes/no) & $10,596 / 117,742$ & $4707(44.4) / 9048(7.7)$ & 9.60 (9.19-10.03) & $<0.001$ & $3.64(3.45-3.83)$ & $<0.001$ \\
\hline
\end{tabular}


Table 5 Prognostic factors influencing mortality rates among hospitalized, Thai, adult, CKD patients (Continued)

\begin{tabular}{|c|c|c|c|c|c|c|}
\hline \multicolumn{7}{|l|}{ Complications } \\
\hline $\begin{array}{l}\text { Anemia requiring blood } \\
\text { Transfusion (yes/no) }\end{array}$ & $38,730 / 89,608$ & $5916(15.3) / 7839$ (8.7) & $1.88(1.81-1.95)$ & $<0.001$ & $1.03(0.98-1.07)$ & 0.28 \\
\hline Hyperkalemia (yes/no) & $19,165 / 109,173$ & $3728(19.5) / 10,027(9.2)$ & $2.39(2.29-2.49)$ & $<0.001$ & $1.48(1.40-1.55)$ & $<0.001$ \\
\hline Volume overload (yes/no) & $15,213 / 113,125$ & 2,831 (18.6)/10,924 (9.7) & $2.14(2.04-2.24)$ & $<0.001$ & $1.23(1.16-1.31)$ & $<0.001$ \\
\hline Metabolic acidosis (yes/no) & $10,561 / 117,777$ & 2,799 (26.5)/10,956 (9.3) & $3.52(3.35-3.69)$ & $<0.001$ & $1.72(1.62-1.82)$ & $<0.001$ \\
\hline \multicolumn{7}{|l|}{ Mode of dialysis } \\
\hline Hemodialysis (yes/no) & $12,175 / 116,163$ & 2,516 (20.7)/11,239 (9.7) & $2.43(2.32-2.55)$ & $<0.001$ & $0.90(0.85-0.96)$ & 0.002 \\
\hline Peritoneal dialysis (yes/no) & $3,509 / 124,829$ & $717(20.4) / 13,038(10.4)$ & $2.20(2.02-2.39)$ & $<0.001$ & $0.87(0.78-0.96)$ & 0.006 \\
\hline
\end{tabular}

Note: CKD chronic kidney disease, ESRD end stage renal disease, UCS Universal Coverage Scheme, CSMBS Civil Servant Medical Benefit Scheme, SHI Social Health Insurance, $\mathrm{Cl}$ confidence interval

to have better benefits than the other schemes; such as free access to specialist care, free service without capitation, and better chances of getting kidney replacement therapy (either hemodialysis or CAPD) for ESRD patients. Furthermore, the ratios of population and ESRD patients per nephrologist and dialysis unit were the best in Bangkok and the central region: that is, the regions where a higher proportion of patients are under either the CSMBS or SHI. On the other hand, in the other regions where most patients are under the UCS, poorer ratios prevail. The insufficiency of medical personnel and equipment might be the reasons for higher CKD complications and less dialysis treatment in the UCS group. Previous studies confirmed that remote CKD patients were less likely to receive specialist care, to receive laboratory testing, and to get appropriate medications, and were more likely to die or be hospitalized compared with those living closer to a nephrologist $[31,32]$.

Table 6 Comparison the health policies on the health care providing and reimbursement among the three schemes

\begin{tabular}{llll}
\hline Issues & SHI & UCS CSMBS \\
\hline Financial barriers to & Acute complications occurred, the patients had access to special care without barrier by referral system.
\end{tabular}
equitable access

Administrative efficiency

Patient and provider autonomy

Non-financial barriers to equitable access

Reimbursement of erythropoietin administration

$\begin{array}{ll}\text { - Pre-dialysis } & \text { No } \\ \text { - Dialysis } & \text { Yes }\end{array}$

Most of the patients worked in the big cities in Bangkok and central region of Thailand which had better population/nephrologist ratio than

UCS

The patients received the care from only the self-registry hospitals (either private or public hospitals). Treatment of ESRD was hemodialysis or CAPD depended on facility of the selfregistry hospitals.
The patients received care only the public hospitals in their casement areas, mostly community or general hospitals. The patients were referred to higher facility hospital whenever the complications occurred. CAPD was the first treatment for ESRD patients.

Most of the patients were in the rural area that had least population/ nephrologist ratio
The patients freely chosen the public or tertiary care hospital that they preferred. Physicians had autonomy to choose hemodialysis or CAPD for treatment of ESRD.

Most of the patient chosen to be care in the tertiary care hospitals and medical school hospitals which had best population/nephrologist ratio

Reimbursement of dialysis for ESRD patients

$$
\begin{aligned}
& \text { - CAPD } \\
& \text { - Hemodyalysis }
\end{aligned}
$$

Yes

Not more than 1,500 bahts (44 USD)/ session and not more than 4,500 bahts (132USD)/week.

$\begin{array}{lc}\text { No } & \text { Yes } \\ \text { Yes } & \text { Yes }\end{array}$

Yes

Yes

Hemodialysis was allowed only CAPD was contraindication or having complications. Not more than 1,5001,700 bahts (44-50 USD)/session and not more than 3,000-3,400 bahts (88100 USD)/week. 
Table 7 Comparing the ratio of population and ESRD patients per one nephrologists and one dialysis unit in different regions

\begin{tabular}{lllll}
\hline $\begin{array}{l}\text { Regional } \\
\text { health care }\end{array}$ & $\begin{array}{l}\text { Population/ } \\
\text { nephrologist } \\
(n)\end{array}$ & $\begin{array}{l}\text { Population/ } \\
\text { dialysis unit } \\
(n)\end{array}$ & $\begin{array}{l}\text { ESRD } \\
\text { patients/ } \\
\text { nephrologist } \\
(n)\end{array}$ & $\begin{array}{l}\text { ESRD } \\
\text { patients/ } \\
\text { dialysis unit } \\
(n)\end{array}$ \\
\hline Bangkok & 44,177 & 51,585 & 71 & 83 \\
Central part & 204,307 & 152,801 & 99 & 74 \\
Northern & 529,820 & 233,121 & 221 & 97 \\
Northeastern & 592,690 & 197,563 & 229 & 76 \\
Southern & 422,429 & 173,941 & 144 & 59 \\
\hline
\end{tabular}

Note: ESRD end stage renal disease

Improving CKD care might be achieved by implementing policies that ensure fairness by providing a comparable budget allocation among the healthcare schemes. The "PD First" policy in Thailand launched in 2008 initiated CAPD as renal replacement therapy for ESRD patients under the UCS [33]. This policy represents an effective strategy for correcting the inadequate distribution of hemodialysis machines and insufficient numbers of nephrologists in rural areas and to underprivileged groups.

Anemia is one of the complications seen in CKD patients, and this can be corrected by injection of erythropoiesis stimulating agent (ESA). ESA is relatively costly and is only reimbursed during the pre-dialysis period under the CSMBS scheme. Our data revealed that there was a lower proportion of patients with anemia requiring blood transfusion under the CSMBS than the UCS or SHI groups. More intensive, high-cost medication support by the 3 main health schemes might reduce morbidity and hospitalization.

The strength of this study is that almost all of the subjects were hospitalized adult, Thai, CKD patients. The results, therefore, provide a clear overview of the situation vis-à-vis these adult patients; however, some limitations existed. Lack of a registered nationwide laboratory system means that there is no standardized staging of CKD patients, which might influence the clinical outcomes. The present study analyzed the administrative claim data, therefore socio-economic status of patients was not available. In addition, we are not able to generate an area locator as a proxy for socioeconomic status of individual patients due to lack of data. Insufficient data of these demand-side characteristics observed at the individual level made some limitations in comparison of equity among the three health insurance schemes. The record of charges for each group represents an average and this might not wholly characterize the severity of individual patients nor include details of the procedures and medical instruments needed for each patient. Moreover, the mortality focused in this study was outcome at discharge which may be different with mortality after discharge because some patients died at home.

\section{Conclusions}

Concerning the treatment of hospitalized CKD patients, the UCS group had the poorest healthcare benefits compared to the other healthcare schemes-e.g., less budget for hospital care (charge cost), poorer access to specialist care, and treatment options that depended on variable healthcare policies. These might explain the greater mortality rate of those under the UCS compared to those under the CSMBS or SHI. In order to improve health outcomes among hospitalized CKD patients, new healthcare policies are needed to improve budget allocations, accessibility to specialist care, and distribution of resources.

\section{Additional files}

Additional file 1: Table S1. Presented characteristics of CKD patients by primary, secondary and total (combined primary and secondary) diagnoses. (DOCX $26 \mathrm{~kb}$ )

Additional file 2: Table S2. Focused on characteristics of CKD patients by the hospital levels. (DOCX $28 \mathrm{~kb}$ )

\begin{abstract}
Abbreviations
AKI: Acute kidney injury; CAPD: Continuous ambulatory peritoneal dialysis; Cl: Confidence interval; CKD: Chronic kidney disease; CSMBS: The Civil Servant Medical Benefit Scheme; DM: Diabetes mellitus; ESA: Erythropoiesis stimulating agent; ESRD: End stage renal disease; GDP: Gross domestic product; GEE: Generalized estimating equation; GFR: Glomerular filtration rate; HIV/AIDS: Human immunodeficiency virus infection and acquired immune deficiency syndrome; HT: Hypertension; ICD: International Statistical Classification of Diseases and Related Health Problems; MLRA: Multiple logistic regression analysis; OR: Odds ratio; SD: Standard deviation; SHI: The Social Health Insurance; UCS: The Universal Coverage Scheme
\end{abstract}

\section{Acknowledgements}

We thank (a) Assoc. Prof. Sumitr Sutra for providing the data (b) Mr. Bryan Roderick Hamman for assistance with the English-language presentation of the manuscript through the Publishing Clinic, Research Affairs, Faculty of Medicine, Khon Kaen University.

\section{Funding}

The study was supported by funding from the Faculty of Medicine, Khon Kaen University and the Thailand Research Fund (IRG \#5780016).

\section{Availability of data and materials}

The additional data for characteristics of CKD patients are available in the Additional files 1 and 2 .

\section{Authors' contributions}

All authors were involved in the conception and study design. CP and CC have collected and clarified data from the three health-scheme offices. Acquisition of data, analysis and interpretation of data were done by SA and KT under the supervision of BT. SA, PM, and BT drafted the manuscript. All authors reviewed and approved the final version of the manuscript.

\section{Competing interests}

The authors declare that they have no competing interests.

Consent for publication

Not applicable. 


\section{Ethics approval and consent to participate}

The Khon Kaen University Ethics Committee for Human Research (KKUEC) reviewed and approved our protocols based on the Helsinki Declaration and the ICH Good Clinical Practice Guidelines. The reference number was HE541036. Since all of the data in the study were from hospital records, written informed consent was not possible. Participants' confidentiality was ensured by data protection and privacy legislation.

\section{Author details}

${ }^{1}$ Department of Medicine, Faculty of Medicine, Khon Kaen University, Khon Kaen Province 40002, Thailand. ${ }^{2}$ Clinical Epidemiology Unit, Faculty of Medicine, Khon Kaen University, Khon Kaen Province 40002, Thailand. ${ }^{3}$ Department of Biostatistics and Demography, Faculty of Public Health, Khon Kaen University, Khon Kaen Province 40002, Thailand.

Received: 6 January 2016 Accepted: 24 September 2016

Published online: 29 September 2016

\section{References}

1. Hsu M, Huang X, Yupho S. The development of universal health insurance coverage in Thailand: Challenges of population aging and informal economy. Soc Sci Med. 2015;145:227-36.

2. Reungjui S, Anunnatsiri S, Limwattananon C, Thavornpitak Y, Pukdeesamai $P$, Mairiang P. Health insurance system and healthcare provision: nationwide hospital admission data 2010. J Med Assoc Thai. 2012;95 Suppl 7:S240-53.

3. Office of the National Economic and Social Development Board, Office of the Prime Minister. Gross Domestic Product at Current Market Prices by Industrial Origin, Whole Kingdom Year: 1995-2013. http://service.nso.go.th/ nso/web/statseries/statseries15.html. Accessed 28 Sep 2016.

4. Tantivess S, Walt G. Using cost-effectiveness analyses to inform policy: the case of antiretroviral therapy in Thailand. Cost Eff Resour Alloc. 2006;4:21.

5. Garabedian LF, Ross-Degnan D, Ratanawijitrasin S, Stephens P, Wagner AK. Impact of universal health insurance coverage in Thailand on sales and market share of medicines for non-communicable diseases: an interrupted time series study. BMJ Open. 2012;2(6):e001686.

6. Beaulière A, Le Maux A, Trehin C, Perez F. Access to antiretroviral treatment in developing countries: Which financing strategies are possible? Rev Epidemiol Sante Publique. 2010;58:171-9.

7. Nattrass NJ. The (political) economics of antiretroviral treatment in developing countries. Trends Microbiol. 2008;16:574-9.

8. Jootar S. CML treatment in Asia-Pacific region. Hematology. 2012;17 Suppl 1:S72-4.

9. Daratha KB, Short RA, Corbett CF, Ring ME, Alicic R, Choka R, et al. Risks of subsequent hospitalization and death in patients with kidney disease. Clin J Am Soc Nephrol. 2012;7:409-16.

10. Go AS, Chertow GM, Fan D, McCulloch CE, Hsu CY. Chronic kidney disease and the risks of death, cardiovascular events, and hospitalization. N Engl J Med. 2004;351:1296-305.

11. World Health Organization (WHO). International classification of diseases version 10 (ICD-10). http://www.who.int/classifications/icd10/. Accessed 28 Sep 2016

12. World Health Organization (WHO). ICD-9-CM 2010 classification of procedures. International classification of diseases 9th revision clinical modification. http://medinfo.psu.ac.th/pr/pr2012//CD/ICD9CM.pdf. Accessed 28 Sep 2016.

13. Anunnatsiri $S$, Reungjui $S$, Thavornpitak $Y$, Pukdeesamai $P$, Mairiang $P$. Disease patterns among Thai adult population: an analysis of data from the hospitalization National Health Insurance System 2010. J Med Assoc Thai. 2012;95 Suppl 7:S74-80

14. Kidney Disease: Improving Global Outcomes (KDIGO) CKD Work Group. KDIGO 2012 clinical practice guideline for the evaluation and management of chronic kidney disease. Kidney Int Suppl. 2013;3:1-150.

15. Yamaguchi J, Kasanuki H, Ishii Y, Yagi M, Ogawa H, Fujii SY, et al. Prognostic significance of serum creatinine concentration for in-hospital mortality in patients with acute myocardial infarction who underwent successful primary percutaneous coronary intervention (from the Heart Institute of Japan Acute Myocardial Infarction [HIJAMI] Registry). Am J Cardiol. 2004;93:1526-8.

16. Meyer A, Bunzemeier $H$, Hausberg M, Walter M, Roeder N, Breithardt G, et al. Impact of different stages of chronic kidney disease on in-hospital costs in patients with coronary heart disease. Nephrol Dial Transplant. 2008;23:1955-60.
17. Szummer K, Lundman P, Jacobson SH, Schön S, Lindbäck J, Stenestrand U, et al. Relation between renal function, presentation, use of therapies and inhospital complications in acute coronary syndrome: data from the SWEDEHEART register. J Intern Med. 2010;268:40-9.

18. Volkmann MA, Behr PE, Burmeister JE, Consoni PR, Kalil RA, Prates PR, et al. Hidden renal dysfunction causes increased in-hospital mortality risk after coronary artery bypass graft surgery. Rev Bras Cir Cardiovasc. 2011;26:319-25.

19. Tessone A, Gottlieb S, Barbash IM, Garty M, Porath A, Tenenbaum A, et al. Underuse of standard care and outcome of patients with acute myocardial infarction and chronic renal insufficiency. Cardiology. 2007;108:193-9.

20. Parikh PB, Jeremias A, Naidu SS, Brener SJ, Lima F, Shlofmitz RA, et al. Impact of severity of renal dysfunction on determinants of in-hospital mortality among patients undergoing percutaneous coronary intervention. Catheter Cardiovasc Interv. 2012;80:352-7.

21. Heywood JT, Fonarow GC, Costanzo MR, Mathur VS, Wigneswaran JR, Wynne J. High prevalence of renal dysfunction and its impact on outcome in 118,465 patients hospitalized with acute decompensated heart failure: a report from the ADHERE database. J Card Fail. 2007;13:422-30.

22. Yang $Y H$, Wang $L, A n F$, Huang JH, Ma JP, Li GP, et al. Renal dysfunction and survival in hospitalized patients with chronic heart failure: a retrospective analysis. Zhonghua Xin Xue Guan Bing Za Zhi. 2009;37:729-33.

23. Chew DP, Astley C, Molloy D, Vaile J, De Pasquale CG, Aylward P. Morbidity, mortality and economic burden of renal impairment in cardiac intensive care. Intern Med J. 2006;36:185-92.

24. Howell NJ, Keogh BE, Bonser RS, Graham TR, Mascaro J, Rooney SJ, et al. Mild renal dysfunction predicts in-hospital mortality and post-discharge survival following cardiac surgery. Eur J Cardiothorac Surg. 2008;34:390-5.

25. Ovbiagele B. Chronic kidney disease and risk of death during hospitalization for stroke. J Neurol Sci. 2011;301:46-50.

26. Tangcharoensathien $\mathrm{V}$, Pitayarangsarit $\mathrm{S}$, Patcharanarumol W, Prakongsai $\mathrm{P}$ Sumalee $H$, Tosanguan J, et al. Promoting universal financial protection: how the Thai universal coverage scheme was designed to ensure equity. Health Res Policy Syst. 2013;11:25.

27. Prakongsai $P$, Limwattananon $S$, Tangcharoensathien $V$. The equity impact of the universal coverage policy: lessons from Thailand. Adv Health Econ Health Serv Res. 2009;21:57-81.

28. Yiengprugsawan V, Kelly M, Seubsman SA, Sleigh AC. The first 10 years of the Universal Coverage Scheme in Thailand: review of its impact on health inequalities and lessons learnt for middle-income countries. Australas Epidemiol. 2010;17:24-6.

29. Ruangratanatrai W, Lertmaharit S, Hanvoravongchai P. Equity in health personnel financing after Universal Coverage: evidence from Thai Ministry of Public Health's hospitals from 2008-2012. Human Res Health. 2015;13:59-66.

30. Tangchareonsathien $V$, Supachutikul A, Lertiendumrong J. The social security scheme in Thailand: what lessons can be drawn? Soc Sci Med. 1999:48:913-23.

31. Rucker D, Hemmelgarn BR, Lin M, Manns BJ, Klarenbach SW, Ayyalasomayajula B, et al. Quality of care and mortality are worse in chronic kidney disease patients living in remote areas. Kidney Int. 2011;79:210-7.

32. Bello AK, Hemmelgarn B, Lin M, Manns B, Klarenbach S, Thompson S, et al. Impact of remote location on quality care delivery and relationships to adverse health outcomes in patients with diabetes and chronic kidney disease. Nephrol Dial Transplant. 2012;27:3849-55.

33. Dhanakijcharoen $P$, Sirivongs D, Aruyapitipan S, Chuengsaman P, Lumpaopong A. The "PD First" policy in Thailand: three-years experiences (2008-2011). J Med Assoc Thai. 2011;94 Suppl 4:S153-61.

\section{Submit your next manuscript to BioMed Central and we will help you at every step:}

- We accept pre-submission inquiries

- Our selector tool helps you to find the most relevant journal

- We provide round the clock customer support

- Convenient online submission

- Thorough peer review

- Inclusion in PubMed and all major indexing services

- Maximum visibility for your research

Submit your manuscript at www.biomedcentral.com/submit 